\title{
Analysis and evaluation of pyrethroid exposure in human population based on biological monitoring of urinary pyrethroid metabolites
}

\author{
Jun UEyama, Isao SAITO ${ }^{\dagger}$ and Michihiro KAMIJIMA ${ }^{\dagger \dagger}, *$ \\ Program in Radiological and Medical Laboratory Sciences, Nagoya University Graduate School of Medicine, \\ 1-1-20 Daikominami, Higashi-ku, Nagoya 461-8673, Japan \\ ${ }^{\dagger}$ Food Safety and Quality Research Center, Tokai COOP Federation, \\ 1-173 Sagamine, Yazako, Nagakute-cho, Aichi 480-1103, Japan \\ ${ }^{\dagger}$ Department of Occupational and Environmental Health, Nagoya City University Graduate School of Medical Sciences, \\ 1 Kawasumi, Mizuho-cho, Mizuho-ku, Nagoya 467-8601, Japan
}

(Received February 13, 2010; Accepted March 3, 2010)

\begin{abstract}
The current risk assessment of human exposure to low-level pyrethroids (PYRs) is generally based on the estimation of residue intake from diets. Limited data are available on individual exposure levels in human studies, which is partly attributable to the difficulty in biological monitoring of PYR exposure. This obstacle has been overcome in recent years due to the evolution of analytical chemistry. Separation and sensitive identification and quantitation of urinary PYR metabolites are today reliably made with liquid chromatography-mass spectrometry and gas chromatography-mass spectrometry. This article gives an overview of the biological monitoring of urinary PYR metabolites, reviews PYR metabolite levels in general populations, and discusses future research perspectives in the field of environmental health. (C) Pesticide Science Society of Japan
\end{abstract}

Keywords: pyrethroid, biological monitoring, metabolite, urine.

\section{Introduction}

Insecticides are chemicals which are used to increase agricultural crop production and maintain a good hygienic condition. The amount of their active ingredients used throughout the world and the United States (US) was 1.2 and 0.1 billion pounds, respectively in $2001,24 \%$ and $9 \%$ of the amount of total pesticide use. In the US, about $70 \%$ of these pesticides were used for agriculture, $14 \%$ for industrial, commercial, and government purposes, and 16\% for home and garden applications. ${ }^{1)}$

Pyrethroids (PYRs) are a class of synthetic insecticides that were developed from prototype pyrethrins to increase their environmental stability and selective insecticidal properties. ${ }^{2)}$ In general, PYRs, the mode of action of which is excitation of the voltage-gated sodium channels, are less toxic to mammals and are considered good candidates to replace more toxic organophosphorus insecticides (OPs). The regulatory phaseout of OPs for residential pest control as well as agricultural

\footnotetext{
* To whom correspondence should be addressed.

E-mail:kamijima@med.nagoya-cu.ac.jp

Published online April 30, 2010

(C) Pesticide Science Society of Japan
}

use has resulted in the increased use of PYRs since the late 1990s in the US. ${ }^{3,4)}$ National estimate of the amount of PYRs applied to cropland in the US showed that approximately 2.4 million pounds, which was the sum of bifenthrin, cyfluthrin, cyhalothrin, cypermethrin, esfenvalerate, fenproparthrin, fenvalerate, permethrin, tefluthrin, and tralomethrin, were used, with the biggest share of permethrin (1 million pounds) ${ }^{5)}$ Of 99,686 tons of insecticides shipped to the market in Japan in 2008, PYRs as active ingredients were estimated to be about 150 tons. ${ }^{6}$ Since PYRs are also used as household insecticides, such as allethrin and resmethrin or repellent, they have today become pesticides in the environment to which people are most frequently exposed.

The average daily intake of permethrin, which is the most frequently used PYR in the US, from the diet is estimated to be about $3.2 \mu \mathrm{g} /$ day, which is about 1,000 times lower than the acceptable daily intake (ADI) of permethrin determined by United Nations' Food and Agriculture Organization and the World Health Organization. ${ }^{7}$ The Ministry of Health, Labour and Welfare in Japan has also reported that the daily dietary intake of PYRs was lower than the ADI. ${ }^{8)}$ These estimations suggest that the dietary pesticide residue regulation by the Joint FAO/WHO Meetings on Pesticide Residues (JMPR) and each government work well, in terms of main- 
taining the PYR exposure level below the ADI; however, there is little information about the actual PYR exposure of each individual in the general population.

From the toxicological viewpoint in PYR research, there have been many laboratory studies using experimental animals with various endpoints, including developmental and reproductive toxicity, mutagenicity and oncogenicity; however, the current risk assessment of long-term exposure of humans to low-level PYRs is not based on human studies. This problem is partly attributable to the difficulty in biological monitoring of PYR exposure via all exposure routes (ingestion, inhalation and dermal absorption). This obstacle has been overcome in recent years due to the development of analytical chemistry; sensitive biomarkers, i.e. urinary metabolites, are being developed. Compared to exposure assessment by an approach to estimate pesticide residue intake from the diet, these biomarkers can provide information more specific to an individual exposure dose and can reflect the exact body burden at the time of measurement.

Urinary PYR metabolites, e.g. 3-phenoxybenzoic acid (3PBA), have been used as the most sensitive biomarker for environmental PYR exposure since the late 1990s. Figure 1 shows the relationship between commonly measured metabolites (shaded areas) and their parent compounds. 3-PBA and chrysanthemumdicarboxylic acid (CDCA) are metabolites common to several PYRs. 3-(2,2-Dichlorovinyl)-2,2-dimethylcyclopropane-1-carboxylic acid (DCCA) is a less specific metabolite derived from cyfluthrin, cypermethrin and permethrin. In contrast, 4-fluoro-3-phenoxybenzoic acid (F-PBA) and cis-3-(2,2-dibromovinyl)-2,2-dimethylcyclopropane-1-carboxylic acid (DBCA) are metabolites specific to a certain PYR; the former is derived from cyfluthrin and the latter from deltamethrin. 3-PBA, DCCA and CDCA are de- tected with high frequency in human urine. Of these, the most frequently measured metabolite in numerous studies is 3PBA. Owing to the improved analytical methodology for 3PBA, it can be used as a biomarker of PYR to assess not only occupational but low-level environmental exposure, which occurs through various routes in the daily activities of life of the general population. ${ }^{9-12)}$ More recently, some researchers have reported the relationship between urinary metabolite levels and several adverse health outcomes in epidemiological studies. ${ }^{13-16)}$ In this review, the biological monitoring of PYR in the general population and its limitations will be discussed.

\section{Possible exposure pathways of PYRs in the general population}

As mentioned above, human exposure to PYR can occur not only via food intake, which includes the residue, but inhalation and dermal absorption. Understanding the primary sources and routes of human exposure to PYRs in daily life is a fundamental step for risk assessment. Urinary PYR metabolites have been measured to address the issue. Lu et al. ${ }^{17)}$ examined the relationship between the body burden of PYRs and children's diets, self-reported residential PYR use, and age. Urinary PYR metabolites in 23 children (3-11 years) were measured in two spot daily urine samples, first-morning and before-bedtime voids, for 15 consecutive days. The conventional diets were substituted with organic food items for the middle 5 consecutive days, although the details of the organic food were unspecified. Daily volume-weighted averages of urinary 3-PBA and trans-DCCA were significantly higher than in children whose parents reported the use of PYRs at home than in those who did not, and significantly higher in older children (8-11 years of age) than in younger children (3-7 years of age). Replacement with organic diets did not

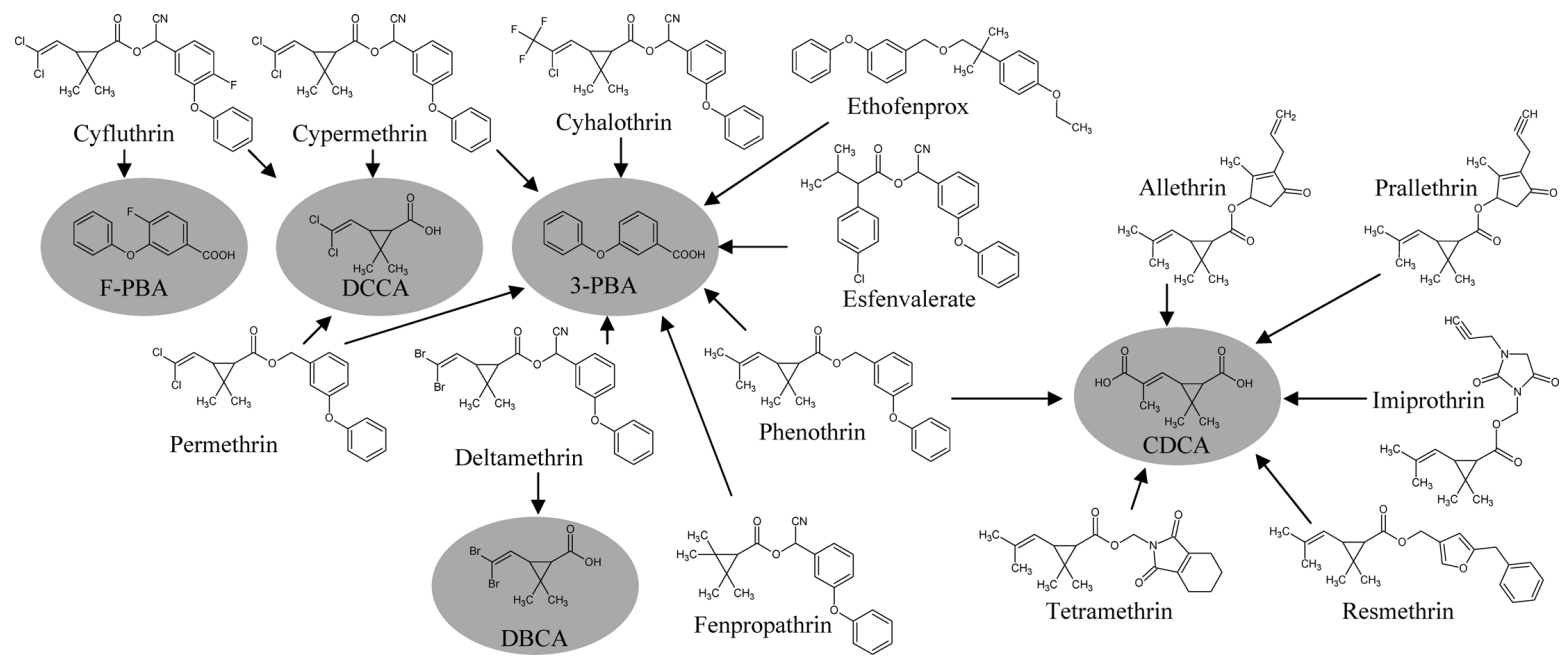

Fig. 1. Synthetic pyrethroids and their urinary metabolites (shaded areas) measured for biological monitoring. This figure was adapted from Starr et $a l .{ }^{22)}$ with slightly modifications. Abbreviations: F-PBA, 4-fluoro-3-phenoxybenzoic acid; DCCA, 3-(2,2-dichlorovinyl)-2,2-dimethylcyclopropane-1-carboxylic acid; 3-PBA, 3-phenoxybenzoic acid; DBCA, cis-3-(2,2-dibromovinyl)-2,2-dimethylcyclopropane-1-carboxylic acid; CDCA, chrysanthemumdicarboxylic acid. 
substantially change the urinary PYR metabolite levels over the time period. They concluded that residential pesticide use represents the most significant factor for children's exposure to PYRs. Moreover, they discussed that age-related metabolite levels were possibly associated with outdoor sports activity levels. One of the limitations of this study was that they could not differentiate exposure to environmental PYRs and to its decomposed residues, which might have resulted in overestimation of the exposed dose of PYRs.

Some researchers have tried to address this important issue. Morgan et al. ${ }^{18)}$ monitored PYR residues in the diet, hand wipes, carpet dust, air from 127 preschool children's houses, and their urinary PYR metabolites. Detection frequencies of cis- and trans-permethrin were $100 \%$ with geometric means of 572 and $453 \mathrm{ng} / \mathrm{g}$, respectively. The maximum estimated PYR exposure level of these children was $480 \mathrm{ng} / \mathrm{kg} / \mathrm{day}$, which is at least 100 times lower than the oral reference dose (RfD) ${ }^{19)}$ The authors estimated the potentially absorbed daily dose in the children through possible exposure routes, and concluded that the relative magnitudes of the exposure to permethrin were as follows: Oral route (e.g., intake from diet and hand-to-mouth activities) $>$ dermal absorption $>$ inhalation. In addition, the estimated intake dose of permethrin accounted for about $60 \%$ of the excreted amounts of urinary 3-PBA. Decomposed PYRs, which are the same compounds as metabolites, reportedly exist in some plants. ${ }^{20,21)}$ Starr et al. ${ }^{22)}$ assessed the relationship between urinary metabolite levels and decomposed PYR levels in house dust. Decomposed PYRs, i.e. 3-(2,2-dimethylvinyl)-2,2-dimethylcyclopropane-1-carboxylic acid (CA), DBCA, DCCA and 3-PBA, were detected in more than half of the dust samples at mean levels of 466, 116,419 and $124 \mathrm{ng} / \mathrm{g}$, respectively. These data suggest that extrapolations from urinary concentrations of PYR metabolites to the PYR exposure level should be made with caution because decomposed PYRs taken into the body are possibly excreted in urine as forms of PYR metabolites. Additional studies are needed to understand how much of the urinary PYR metabolite level comes from such 'metabolite' exposure.

\section{Toxicokinetics of PYR in humans}

In mammals, the hydrolysis of PYRs is a major pathway of detoxification. The metabolic pathway from permethrin to 3PBA is shown in Fig. 2. PYRs, such as permethrin, cypermethrin, deltamethrin, phenothrin and cyhalothrin, are metabolized by carboxylesterase, ${ }^{23)}$ resulting in the generation of 3phenoxybenzyl alcohol (3-PBAlc). 3-PBAlc is metabolized to 3-phenoxybenzaldehyde (3-PBAld) by alcohol-dehydrogenase (ADH), and further metabolized to 3-PBA by aldehyde-dehydrogenase (ALDH) ${ }^{24)}$ Nakamura et $a l .{ }^{23)}$ have reported that cytochrome P450 (CYP) plays a metabolic role in part of this alcohol and aldehyde oxidation. Eventually, 3-PBA is excreted into urine and/or bile via glucuronidation and other conjugation procedures. ${ }^{25}$ ) 3 -PBA and DCCA are excreted into urine mainly in free $(1-10 \%$ and $1-8 \%$ of the adminis-

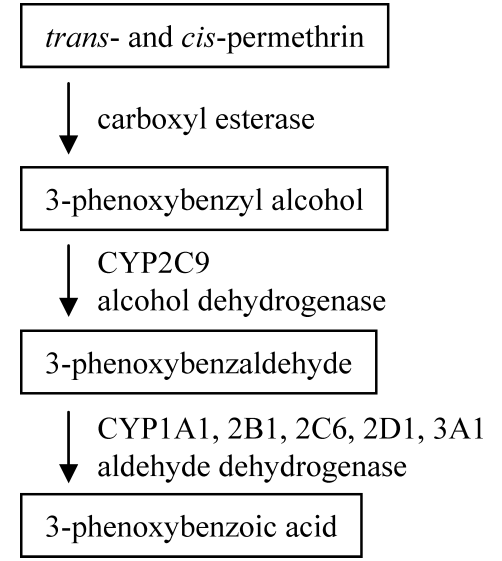

Fig. 2. Metabolic pathway of permethrin in mamals. Abbreviations: CYP, cytochrome P450.

tered dose, respectively) and glucuronide $(7-15 \%$ and $14-42 \%$, respectively) forms. In addition to glucuronide, glycine and glutamic acid conjugated forms of 3-PBA, and taurine and lactone conjugated forms of DCCA are found in urine. ${ }^{25)}$ Thus, it is reasonable to suppose that the 3-PBA excretion rate might change depending on population- and gender-related differences in the expression and activity of the carboxylesterase, ADH, ALDH, CYP and UDP-glucuronosyltransferase isozymes in the liver and other organs, as suggested from experimental studies. ${ }^{26-33)}$

So far, there are few human data on the toxicokinetics of PYRs. When cypermethrin was administered orally to male human volunteers as a single dose of $8 \mathrm{mmol}$, about $1.6 \mathrm{mmol}$ 3 -PBA and $4.3 \mathrm{mmol}$ DCCA (sum of free and glucuronide forms) were excreted in urine by $120 \mathrm{~h}$ after administration. The half-life of the urinary metabolites was about $16 \mathrm{~h} .{ }^{34)}$ Leng et $a l .{ }^{35)}$ estimated that the half-life of urinary PYR metabolites was 6-7 $\mathrm{h}$ for DCCA and 4-fluoro-3-phenoxybenzoic acid (F-PBA) from an experiment in which cyfluthrin was orally administered to human volunteers. After cyfluthrin administration, $93 \%$ of the metabolites were eliminated during the first $24 \mathrm{~h}$. This information can help to estimate the extent of PYR exposure when the length of time after dosing is known.

Due to the variety of insecticides used in the environment, both occupational and environmental exposures occur as coexposure to mingled insecticides. Moreover, formulated commercial insecticide products contain diluents, additives, and other inert ingredients in addition to active ingredients. Studies have indicated that some OPs inhibit the metabolism of PYRs by decreasing the activity of esterases involved in the first step of their metabolic pathway. ${ }^{25)}$ Timchalk et al. ${ }^{36)}$ reported that binary exposure to chlorpyrifos (CPF) and diazinon (DZN) did not affect the pharmacokinetics of the parent compounds in rats, whereas the amount of 24-h urinary excretion of CPF metabolite, 3,5,6-trichloro-2-pyridinol, was de- 
creased. Thus, when PYR exposure levels are estimated by biological monitoring of the urinary PYR metabolite levels, it should be considered that the amount of PYR metabolite excretion might be affected by co-exposure to OPs. Further study is needed to elucidate the effect of co-exposure to PYR and other chemicals on the excretion level of urinary PYR metabolites not only in experimental animals but also the human body. Whether toxicity with such co-exposure is increased should also be investigated since only a few studies have characterized the effects in experimental animals. ${ }^{36,37)}$

\section{Analytical methods for PYR metabolites in biological samples}

The analytical methods reported for PYR metabolites are outlined in Table 1. It is not easy to analyze the metabolites because of their low urinary concentrations, indispensable expensive analytical equipment, such as gas or liquid chromatograph/mass spectrometer, and the complicated procedure needed to extract metabolites from biological samples and/or to derivatize the metabolites. In general, the measurements of PYR metabolites are comprised of three main steps: (1) transforming the conjugates into the free form; (2) extraction of the free form from urine, and its concentrating and derivatization procedure; (3) detection and quantitation.

As mentioned in the previous section, PYR metabolites are excreted in the urine not only in a free form but in some conjugated forms. To evaluate the total body burden of PYRs more precisely and to increase analytical sensitivity, conjugated PYR metabolites have to be converted into the free form by either heating under strongly acidic conditions or an enzymatic (e.g. $\beta$-glucuronidase and sulfatase) reaction. As for the second step, there are mainly two extraction methods, i.e. liquid-liquid extraction (LLE) and solid phase extraction (SPE). Each of these methods has its respective merits and demerits. SPE is superior to LLE in terms of its higher selectivity, easier handling, and reduction of hazardous extraction solvents; however, the higher cost is the problems of SPE. The method requires an expensive SPE column and many washing steps. With regard to the third step, methods using gas chromatography-mass spectrometry (GC-MS) or liquid chromatography-atmospheric pressure ionization-tandem mass spectrometry (LC-MS/MS) have been developed to detect urinary PYR metabolites, and these sophisticated analytical tools have inherent advantages in terms of the speed of analysis, high selectivity and sensitivity, and low labor intensiveness. The major advantage of the LC-MS/MS-based method is its potential to analyze various metabolites simultaneously with substantially simple pretreatment of a sample; however, these advantages are partially counterbalanced by the higher instrument cost in comparison with GC-MS systems. Moreover, the sensitivity of PYR metabolite measurements using LCMS/MS at present tends to be lower than using GC-MS. The sensitivity of the GC-MS method for 3-PBA and DCCA is sufficient to monitor low-level PYR exposure in the general population in epidemiological studies, since the metabolites are detected in nearly $100 \%$ of study participants in population studies. ${ }^{12,38,39)}$

Recently, immunoassays for urinary PYR metabolites, such as 3-PBAlc, 3-PBA and DCCA, have been developed. ${ }^{40-42)}$ The limit of quantitation of a competitive indirect enzymelinked immunosorbent assay (ELISA) for cis/trans-DCCAglycine has become as low as $1.0 \mu \mathrm{g} / 1{ }^{40)}$ More recently, Kim et al. $^{43)}$ reported an anti-immunocomplex assay for the detection of urinary 3-PBA. The recovery for 3-PBA-spiked urine was $98 \%$ with coefficients of variation of $8.2 \%$ or less at a concentration of $5 \mu \mathrm{g} / \mathrm{l}$. Although the limit of detection (LOD) and limit of quantitation were not presented, these validation data met the requirement for biological monitoring of occupational PYR exposure, but not of environmental exposure in general populations. In the future, however, these immunoassays, which do not need expensive analytical equipment and are thus feasible even in developing countries, might become a powerful tool for providing information on the absorbed dose in individuals.

One aspect to be noted here is the compatibility of data sets reported from different laboratories. In this regard, only one study is available that cross validated multiple methods for measuring PYR metabolites in human urine. ${ }^{44)}$ This validation study reported that similar results could be obtained for various combinations of sample preparation (SEP or LLE) and detection methods (GC-MS with electron ionization and in negative ion chemical ionization mode, or LC-MS/MS). The findings indicated that comparable results within a reasonable margin of error could be attained, at least for the examined methods. Thus, each laboratory which analyzes PYR metabolite concentrations is recommended to participate in an external quality assessment scheme for biological monitoring. One of the programs is organized by Prof. Hans Drexler at the Institute and Outpatient Clinic of Occupational, Social and Environmental Medicine at the University of Erlangen-Nuremberg, Germany (http://www.g-equas.de/). This program is geared toward occupational PYR exposure under which the expected concentrations of urinary PYR metabolites are relatively higher than in general population.

The final discussion in this section concerns urine collection from babies. All of the published epidemiological studies measuring PYR metabolites have targeted populations aged over two years old due to difficulties in urine collection from diapers. Although no epidemiological data were presented, $\mathrm{Hu}$ et al. $^{45)}$ attempted to measure PYR metabolites from disposable diapers. If the analytical sensitivities are improved further, the method will be suitable for epidemiological field studies on children using diapers.

\section{Reported PYR metabolite levels in individuals without occupational exposure}

Papers that have reported PYR exposures among general populations within a specific age range, such as children, the elderly 


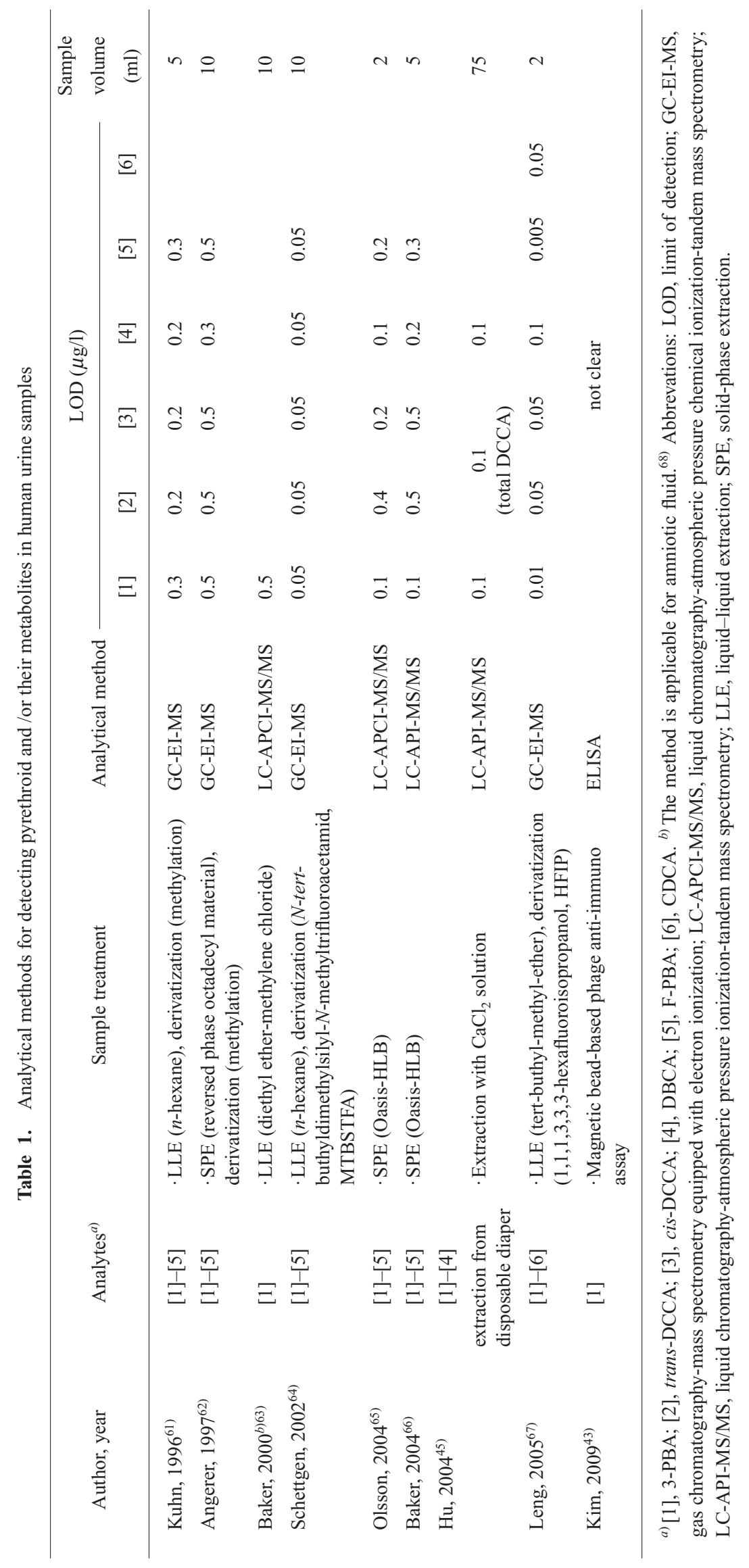




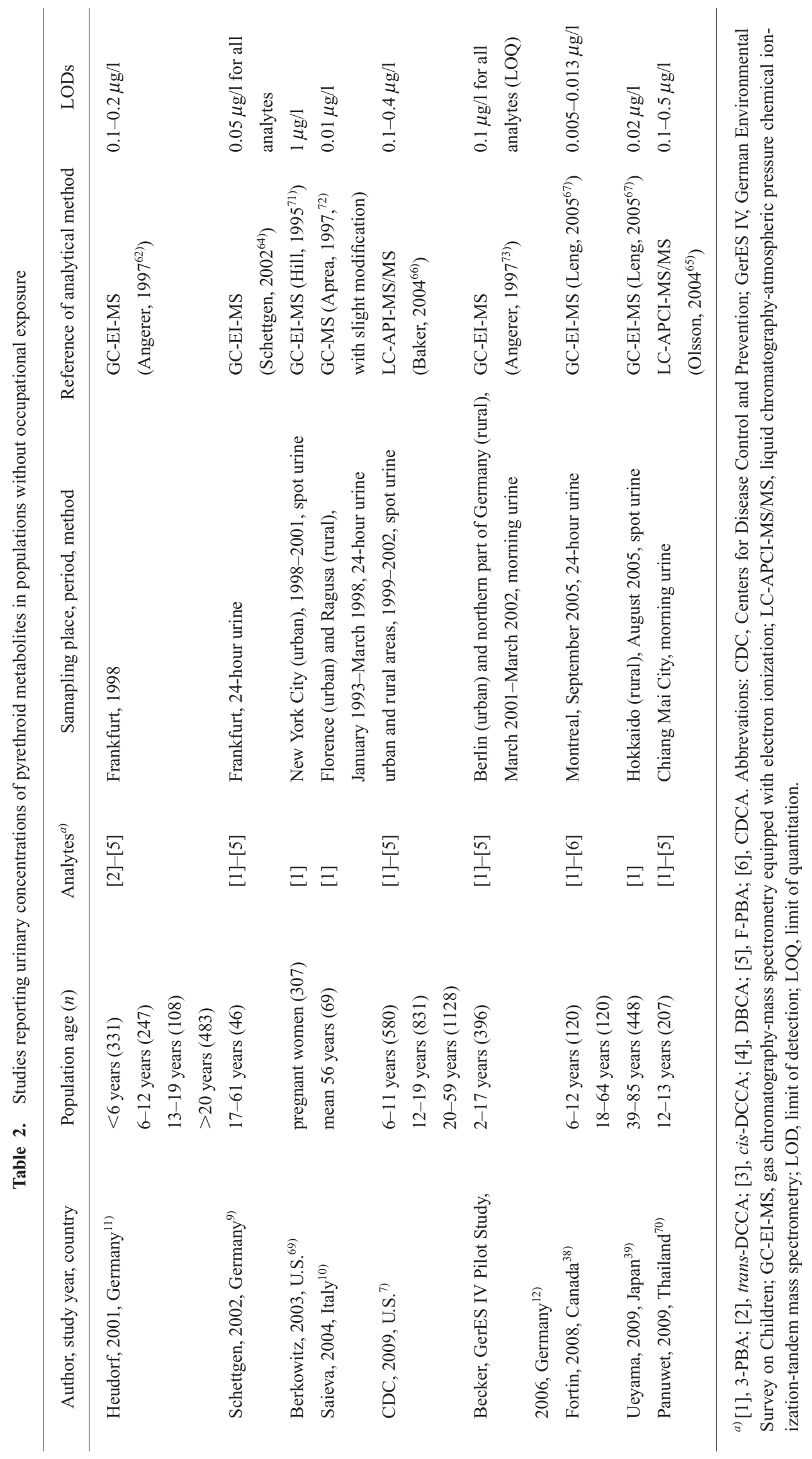




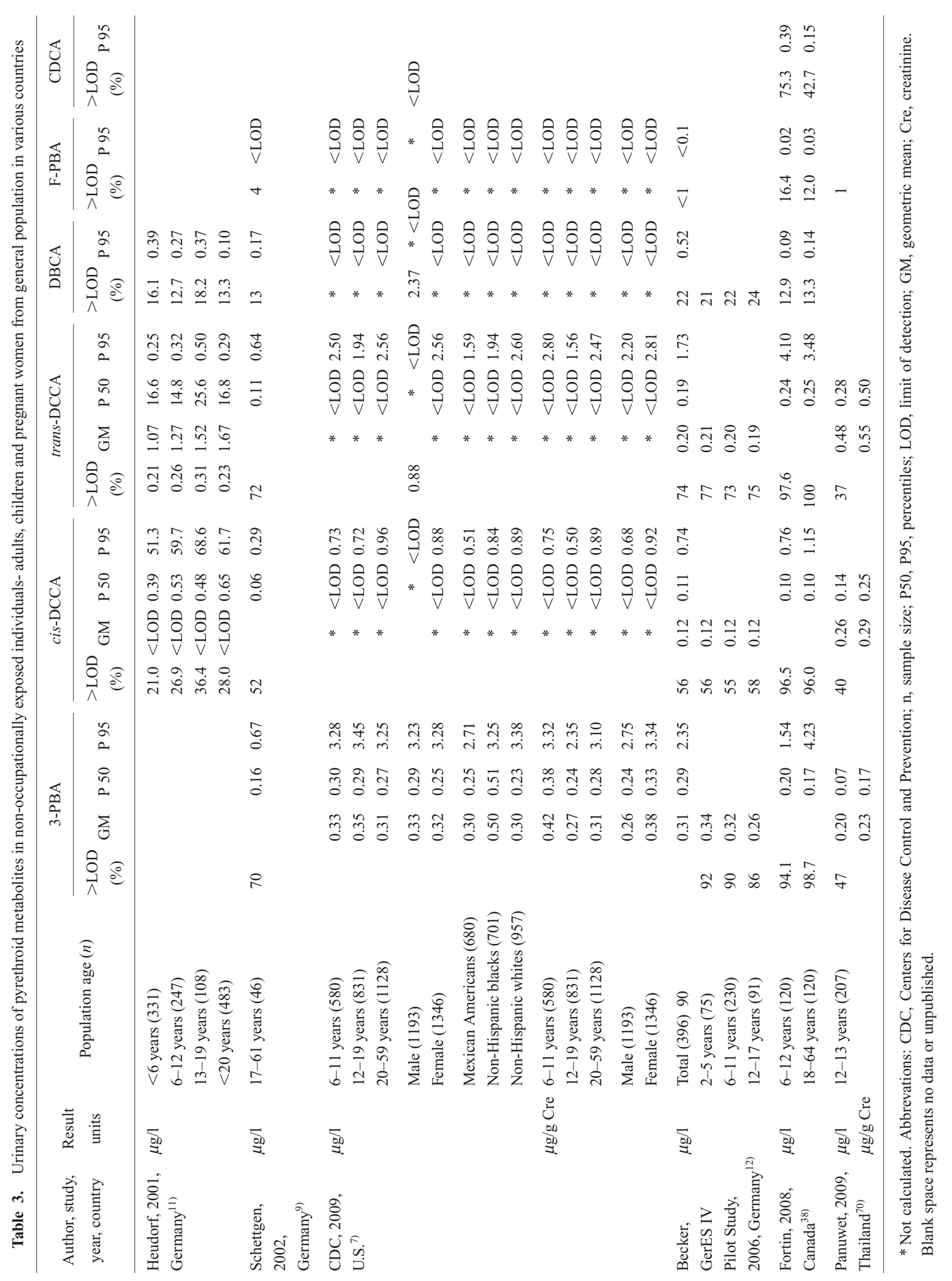


Table 3. (Continued)

\begin{tabular}{|c|c|c|c|c|c|c|}
\hline \multirow{2}{*}{ Author, study, year, country } & \multirow{2}{*}{ Result units } & \multirow{2}{*}{ Population age $(n)$} & \multicolumn{4}{|c|}{ 3-PBA } \\
\hline & & & $>\operatorname{LOD}(\%)$ & GM & P 50 & P 95 \\
\hline \multirow[t]{5}{*}{ Berkowitz, 2003, U.S. ${ }^{69)}$} & $\mu \mathrm{g} / \mathrm{g}$ Cre & $<20$ years $(137)$ & & & 13.3 & \\
\hline & & $20-24$ years $(127)$ & & & 19.3 & \\
\hline & & $25-29$ years $(43)$ & & & 16.8 & \\
\hline & & $30-34$ years $(57)$ & & & 22.7 & \\
\hline & & $\geq 35$ years $(22)$ & & & 80.1 & \\
\hline \multirow[t]{3}{*}{ Saieva et al., 2004, Italya)10) } & $\mu \mathrm{g} / \mathrm{day}$ & mean 56 years & & & & \\
\hline & & urban area (51) & 61 & 0.88 & 1.20 & \\
\hline & & rural area (18) & 33 & 0.71 & 1.78 & \\
\hline \multirow[t]{8}{*}{ Ueyama, 2009, Japan ${ }^{39)}$} & $\mu \mathrm{g} / 1$ & Total (448) & 98 & 0.29 & 0.29 & 1.96 \\
\hline & & $40-49$ years $(52)$ & & 0.26 & 0.25 & 1.53 \\
\hline & & $50-69$ years $(304)$ & & 0.31 & 0.30 & 2.07 \\
\hline & & $70-85$ years $(92)$ & & 0.26 & 0.27 & 2.08 \\
\hline & & Male (143) & & 0.32 & 0.31 & 2.06 \\
\hline & & Female (305) & & 0.28 & 0.28 & 1.89 \\
\hline & $\mu \mathrm{g} / \mathrm{g}$ Cre & Male (143) & & 0.32 & 0.28 & 2.08 \\
\hline & & Female (305) & & 0.45 & 0.44 & 2.61 \\
\hline
\end{tabular}

a) Unit used in the report were transformed from nmol to ug. Abbrevations: n, sample size; P50, P95, percentiles; LOD, limit of detection; GM, geometric mean; Cre, creatinine. Blank space represents no data or unpublished.

and pregnant women, have rapidly increased since 2001, concomitantly with methodological development. These population-based studies on urinary PYR metabolites are summarized in Table 2, the results of which are summarized in Table 3.

In Germany, reference values for urinary cis- and transDCCA and 3-PBA were established provisionally by the Human Biomonitoring Commission of the German Federal Environmental Agency, primarily based on data gained by representative studies, ${ }^{46)}$ but not established for DBCA and FPBA due to the low detection frequency. Reference values for PYR metabolites in general populations are as follows: 3PBA $2 \mu \mathrm{g} / 1$, cis-DCCA $1 \mu \mathrm{g} / 1$ and trans-DCCA $1 \mu \mathrm{g} / 1$. These values are of course generally lower than those detected in populations with occupational exposure; geometric means of urinary 3-PBA of pest control operators (PCOs) who sprayed PYRs within 2 days before urine collection were $12.3 \mu \mathrm{g} / \mathrm{g}$ creatinine (range, $<$ LOD-226) for summer season and $5.5 \mu \mathrm{g} / \mathrm{g}$ creatinine (range, <LOD-76) for winter. ${ }^{47)}$ Hardt and Angerer ${ }^{48)}$ have reported that the median levels of urinary 3 -PBA in agriculture workers ( $n=19,24$ urine samples), PCOs ( $n=15,29$ urine samples) and greenhouse workers ( $n=2,7$ urine samples) were $0.6 \mu \mathrm{g} / 1$ (range, $<$ LOD-28.5), $1.4 \mu \mathrm{g} / 1$ (range, $<\mathrm{LOD}-57.5$ ) and $2.9 \mu \mathrm{g} / 1$ (range, $<\mathrm{LOD}-$ 26.0), respectively. It should be emphasized that reference values are merely statistically derived without consideration of the health status and thus cannot be used to discuss causal relationships between exposure and health outcomes of the individuals.

Children may live at higher health risk in terms of pesticide exposure than adults since children's daily activities are quite different from those of adults, given their proximity to floors, carpets, lawns, and soil, and the frequency and duration of their hand-to-mouth activity. ${ }^{49)}$ In addition, tissues, organs, biological systems, and detoxification mechanisms for children are undergoing rapid growth. Thus, more severe consequences of toxic effects may occur during the developmental stage rather than after reaching maturity, which is why the level of environmental PYR exposure of children and pregnant women has been a focus of attention. Fortin et al. ${ }^{38)}$ found that urinary CDCA concentrations among children were higher than in adults while concentrations of other PYR metabolites were not different, as reported by other authors (Table 3). On the other hand, $\mathrm{CDC}^{7)}$ and Becker et al. ${ }^{12)}$ reported that urinary PYR and OP metabolite levels were higher in children than in adults. More research on this issue is required worldwide.

When looking at data reported from different institutions, it should be kept in mind that each study adopted various analytical techniques. Since no external quality control survey for measurements of urinary PYR metabolites in a low concentration range has been established, the following issues need to be taken into consideration. 
Urinary metabolite levels are usually reported as volumeweighted concentrations (e.g., $\mu \mathrm{g} / \mathrm{l})$ or creatinine-adjusted concentrations (e.g., $\mu \mathrm{g} / \mathrm{g}$ creatinine) when measured in spot urine samples. The method of urine collection, i.e., spot sample collected at certain times, multiple spot samples over several days or pooled voids over time (e.g., 24-hour urine), is one of the critical methodological factors for assessment of the daily PYR exposure level. Given that the half-lives of urinary metabolites are relatively short, it is better to determine the total amount of metabolites from urine collected over a longer period of time (e.g., 24-hour urine collection); however, such a collection method demands participants' compliance and is usually not feasible, except in hospital settings. Therefore, spot urine samples have been used in many epidemiological studies (Table 2).

Creatinine-adjusted PYR metabolite values have been frequently used for statistical analyses; however, more recently, Fortin et al. ${ }^{38)}$ suggested that insecticide metabolite measure- ments from spot urine samples may lead to serious errors in the estimation of the actual daily absorbed doses, particularly at the individual level, even if adjusted for creatinine contents. The concentration of urinary metabolites may depend on the rates of urinary flow and creatinine excretion. Further studies are needed to establish a feasible and scientifically acceptable data collection method to reflect total 24-h excretion level.

The most frequently measured metabolite in urine is 3PBA, due to its high detection ratio. In recent studies, except those using LC-MS/MS for analysis, the metabolites are detected at nearly $100 \%$ of study participants in the general population. $^{12,38,39)}$ Considering that 3-PBA is derived from representative PYRs, a higher detection ratio of 3-PBA than with other PYR metabolites is a predictable consequence. Although CDCA is also derived from some PYRs, studies reporting urinary CDCA concentrations have been rarely published. ${ }^{38)}$ This is partly because the standard substance of CDCA is hardly available in commercial markets. Since the

Table 4. Summary of literature on environmental pyrethroid exposure and the results

\begin{tabular}{|c|c|c|c|c|}
\hline Author, year & Population & Outcome measured & Statistical analysis & Results \\
\hline Han, $2008^{16)}$ & $\begin{array}{l}207 \text { men recruited } \\
\text { from an infertility } \\
\text { clinic in China }\end{array}$ & $\begin{array}{l}\cdot 3 \text {-PBA adjusted by } \\
\text { urine creatinine } \\
\cdot \text { serum reproductive } \\
\text { hormon level }\end{array}$ & $\begin{array}{l}\text { Multiple linear } \\
\text { regression model }\end{array}$ & $\begin{array}{l}\text { There were positive associations between the } \\
\text { levels of serum LH and 3-PBA ( } p=0.013 \text { ) but } \\
\text { negative associations between E2 and 3-PBA } \\
\text { levels ( } p=0.022 \text { ). }\end{array}$ \\
\hline Xia, 2008 $8^{13)}$ & $\begin{array}{l}376 \text { men diagnosed } \\
\text { with unexplained } \\
\text { male factor infertility } \\
\text { in China }\end{array}$ & $\begin{array}{l}\cdot 3 \text {-PBA adjusted by } \\
\text { urine creatinine } \\
\cdot \text { semen characteristics } \\
\text { such as the } \\
\text { concentration, motility } \\
\text { and progression }\end{array}$ & $\begin{array}{l}\text { Multiple linear } \\
\text { regression model and } \\
\text { logistic regression } \\
\text { model }\end{array}$ & $\begin{array}{l}\text { There was a suggestive association between } \\
\text { increased 3-PBA and sperm concentration } \\
\text { (odd ratios for first, second, third, and fourth } \\
\text { quartiles were } 1.00,1.31,1.73 \text { and } 2.04 \text {, } \\
\text { respectively). }\end{array}$ \\
\hline Meeker, 2008 ${ }^{15)}$ & $\begin{array}{l}207 \text { men recruited } \\
\text { from general } \\
\text { population in U.S. }\end{array}$ & $\begin{array}{l}\cdot 3 \text {-PBA and DCCA } \\
\text { adjusted by urine } \\
\text { creatinine } \\
\cdot \text { semen characteristics } \\
\text { such as the } \\
\text { concentration, motility } \\
\text { and DNA damage } \\
\text { using comet assay }\end{array}$ & $\begin{array}{l}\text { Multiple linear } \\
\text { regression model and } \\
\text { multiple logistic } \\
\text { regression model }\end{array}$ & $\begin{array}{l}\text { - The highest } 3 \text {-PBA quartile was associated with } \\
\text { a suggestive } 20 \text { million sperm/ml reduction in } \\
\text { sperm concentration compared with men below the } \\
\text { median } \\
\text { - In multiple logistic analysis, there were } \\
\text { dose-dependent increased odds below reference } \\
\text { sperm concentration, mortility and morphology } \\
\text { in relation to TDCCA } \\
\text {-3-PBA and cis-DCCA were associated with } \\
\text { increased sperm DNA damage }\end{array}$ \\
\hline Meeker, 2009 $9^{14)}$ & $\begin{array}{l}161 \text { men from an } \\
\text { infertility clinic in } \\
\text { U.S. }\end{array}$ & $\begin{array}{l}\cdot 3 \text {-PBA and DCCA } \\
\text { adjusted by urine } \\
\text { creatinine } \\
\text { - serum reproductive } \\
\text { and thyroid hormon } \\
\text { levels }\end{array}$ & $\begin{array}{l}\text { Multivariable linear } \\
\text { regression model }\end{array}$ & $\begin{array}{l}\text { Significant associations were found as follows; } \\
\cdot \text { FSH/positively/3-PBA and cis- and } \\
\text { trans-DCCA ( } p \text {-values for trend }<0.03) \\
\cdot \text { Testosterone/inversely/total PYR metabolites } \\
(p \text {-values for trend }<0.03)\end{array}$ \\
\hline
\end{tabular}

Abbrevations: TDCCA, cis-plus trans-DCCA; LH, luteinizing hormone; E2, estradiol; FSH, follicle stimulating hormone. 
consumption of parent compounds of CDCA, such as allethrin, resmethrin and tetramethrin, is expected to increase in households, biological monitoring of urinary CDCA may be more important than ever.

\section{Relationship between PYR metabolite concentrations in urine and other biological parameters in the general population}

The primary target of PYRs is the voltage-dependent sodium channel. Its low sensitivity in mammals ensures low acute toxicity. Recently, animal and in vitro studies suggest that some PYRs may disrupt the immune function, ${ }^{50,51)}$ produce oxidative stress, ${ }^{52-55)}$ and possess male reproductive toxicity by disrupting testosterone biosynthesis due to diminishing the delivery of cholesterol into the mitochondria and the conversion of cholesterol to pregnenolone in Leydig cells. ${ }^{56)}$ Moreover, it has been reported that the PYR metabolites, 3-PBAlc and 3-PBAld, possess estrogenic activity of approximately $10^{5}$ less than that of $17 \beta$-estradiol. ${ }^{57,58)}$ These experimental data, although the tested dose was not necessarily low, could provide a new explanation for some of the findings observed in human studies.

In humans, several studies on populations occupationally exposed to PYRs suggest an association of exposure with the possible reduction in semen quality and increased DNA damage in sperm. ${ }^{59,60)}$ Recent several non-occupational studies have suggested that environmental PYR exposure might be associated with circulating hormone levels and semen parameters (Table 4). Urinary PYR metabolites were measured as a biomarker of PYR exposure in each paper. Two studies on Chinese men diagnosed with unexplained male-factor infertility reported that urinary PYR metabolites were associated with altered semen quality, increased serum luteinizing hormone and reduced serum estradiol levels. ${ }^{13,16)}$ Meeker et $a l{ }^{14,15)}$ reported that increased sperm DNA damage identified by comet assay, and reduced serum inhibin B and testosterone may relate to urinary PYR metabolites among the US general population. These lines of evidence suggest that long-term PYR exposure might induce adverse effects in the reproductive system of adult men, although the dose-response relationship of the above findings should be investigated further. It also remains unclear whether these significant alterations in reproductive hormones and sperm indices could result in reduced fertility. Further human studies are required on possible reproductive toxicity in order to achieve more precise risk assessment and control, which are necessary to relieve public health concerns and to continue taking advantage of indispensable PYRs for human health.

\section{Conclusions}

Biological monitoring of low-level PYR metabolites in urine is an effective way to identify the PYR exposure level in individuals, ensuring the safety of food, the living environment and occupational exposure. Although toxicological mecha- nisms are not fully clarified, it seems possible that chronic exposure to PYR may be associated with human body responses other than those in the nervous system, which is the primary target of most insecticides. This point should be addressed in future human studies in which no observed adverse effect level has been determined. For that purpose, it is necessary to: (1) establish analytical methods for PYR metabolites which are sensitive enough to monitor environmental exposure and are feasible for more laboratories and researchers; and (2) conduct research clarifying the dose-response relationship between PYR exposure and health outcomes. It appears certain that biological monitoring of urinary PYR metabolites can play a pivotal role in providing concrete evidence of the best use of PYR and thus ensure human well-being and health.

\section{References}

1) U.S.EPA., Pesticides Industry Sales and Usage. (2004) Available at $\langle\mathrm{http} / / /$ www.epa.gov/oppbead1/pestsales/01pestsales/market_ estimates2001.pdf $\rangle$

2) J.E. Casida: Environ. Health Perspect. 34, 189-202 (1980).

3) J. LaDou (eds.): "Current Occupational \& Environmental Medicine," McGraw Hill, New York.

4) D. Oros and I. Werner: Pyrethroid Insecticides: An Analysis of Use Patterns, Distributions, Potential Toxicity and Fate in the Sacramento-San Joaquin Delta and Central Valley. (2005). Available at $\langle$ http://www.sfei.org/cmr/reports/415_Pyrethroids_ WhitePaper_FINAL.pdf $\rangle$

5) ATSDR: Toxicological Profile for Pyrethrins and Pyrethroids. US Department of Health Human Services, Agency for Toxic Substances and Disease Registry. (2003). Available at $\langle$ http://www.atsdr.cdc.gov/toxprofiles/tp155.pdf $\rangle$.

6) Nouyaku-Youran, Japan Plant Protection Association (2009) (in Japanese).

7) Centers for Disease Control and Prevention (CDC), Fourth National Report on Human Exposure to Environmental Chemicals. (2009). Available at 〈http://www.cdc.gov/exposurereport/pdf/ FourthReport.pdf $>$

8) Japanese Organization of the Ministry of Health. (2008). Available at 〈http://www.ffcr.or.jp/Zaidan/mhwinfo.nsf/ 98a5d7b766af9bfb492565a10020c601/3534736ef68e26b84925 7156000dba70/\$FILE/_12284g44ld5432d8_pdf $\rangle$ (in Japanese).

9) T. Schettgen, U. Heudorf, H. Drexler and J. Angerer: Toxicol. Lett. 134, 141-145 (2002).

10) C. Saieva, C. Aprea, R. Tumino, G. Masala, S. Salvini, G. Frasca, M. C. Giurdanella, I. Zanna, A. Decarli, G. Sciarra and D. Palli: Sci. Total Environ. 332, 71-80 (2004).

11) U. Heudorf and J. Angerer: Environ. Health Perspect. 109, 2137 (2001)

12) K. Becker, M. Seiwert, J. Angerer, M. Kolossa-Gehring, H. W. Hoppe, M. Ball, C. Schulz, J. Thumulla and B. Seifert: Int. J. Hyg. Environ. Health 209, 221-233 (2006).

13) Y. Xia, Y. Han, B. Wu, S. Wang, A. Gu, N. Lu, J. Bo, L. Song, N. Jin and X. Wang: Fertil. Steril. 89, 1743-50 (2008).

14) J. D. Meeker, D. B. Barr and R. Hauser: Reprod. Toxicol. 27, 155-160 (2009). 
15) J. D. Meeker, D. B. Barr and R. Hauser: Hum. Reprod. 23, 1932-1940 (2008).

16) Y. Han, Y. Xia, J. Han, J. Zhou, S. Wang, P. Zhu, R. Zhao, N. Jin, L. Song and X. Wang: Chemosphere 72, 785-790 (2008).

17) C. Lu, D. B. Barr, M. Pearson, S. Bartell and R. Bravo: Environ. Health Perspect. 114, 1419-1423 (2006).

18) M. K. Morgan, L. S. Sheldon, C. W. Croghan, P. A. Jones, J. C. Chuang and N. K. Wilson: Environ. Res. 104, 266-274 (2007).

19) U.S.EPA., Integrated Risk Information System. (2009) Available at $\langle\mathrm{http}: / / \mathrm{www} . e p a . g o v /$ ncea/iris/subst/0185.htm $\rangle$

20) K. Ohsawa and J. E. Casida: J. Agric. Food Chem. 28, 250-255 (1980).

21) L. C. Gaughan and J. E. Casida: J. Agric. Food Chem. 26, 525528 (1978).

22) J. Starr, S. Graham, D. Stout, 2nd, K. Andrews and M. Nishioka: Environ. Res. 108, 271-279 (2008).

23) Y. Nakamura, K. Sugihara, T. Sone, M. Isobe, S. Ohta and S. Kitamura: Toxicology 235, 176-184 (2007).

24) E. Hodgson: J. Biochem. Mol. Toxicol. 17, 201-206 (2003).

25) WHO, Permethrin. Environmental Health Criteria Permethrin, World Health Organization, Geneva 94 (1990).

26) Y. Alnouti and C.D. Klaassen: Toxicol. Sci. 101, 51-64 (2008).

27) G. D. Anderson: Int. Rev. Neurobiol. 83, 1-10 (2008).

28) R. Bellott, V. Le Morvan, V. Charasson, A. Laurand, M. Colotte, U. M. Zanger, K. Klein, D. Smith, J. Bonnet and J. Robert: Cancer Chemother. Pharmacol. 61, 481-488 (2008).

29) M. E. Quintanilla, L. Tampier, A. Sapag, Z. Gerdtzen and Y. Israel: Am. J. Physiol. Endocrinol. Metab. 293, E531-E537 (2007).

30) M. K. Shelby, N. J. Cherrington, N. R. Vansell and C. D. Klaassen: Drug Metab. Dispos. 31, 326-333 (2003).

31) T. Takeuchi, O. Tsutsumi, N. Nakamura, Y. Ikezuki, Y. Takai, T. Yano and Y. Taketani: Biochem. Biophys. Res. Commun. 325, 549-554 (2004).

32) C. Yu, J. K. Ritter, R. J. Krieg, B. Rege, T. H. Karnes and M. A. Sarkar: Drug. Metab. Dispos. 34, 621-627 (2006).

33) X. Zhu, D. Y. Lee and W. G. Shin: Biopharm. Drug Dispos. 28, 125-133 (2007).

34) M. F. Wilkes, B. H. Woollen, J. R. Marsh, P. L. Batten and G. Chester: Int. Arch. Occup. Environ. Health 65, S189-S192 (1993).

35) G. Leng, K. H. Kuhn and H. Idel: Sci. Total Environ. 199, 173181 (1997).

36) C. Timchalk, T. S. Poet, M. N. Hinman, A. L. Busby and A.A. Kousba: Toxicol. Appl. Pharmacol. 205, 31-42 (2005).

37) D. Ortiz, L. Yanez, H. Gomez, J.A. Martinez-Salazar and F. Diaz-Barriga: Ecotoxicol. Environ. Saf. 32, 154-158 (1995).

38) M. C. Fortin, M. Bouchard, G. Carrier and P. Dumas: Environ. Res. 107, 343-350 (2008).

39) J. Ueyama, A. Kimata, M. Kamijima, N. Hamajima, Y. Ito, K. Suzuki, T. Inoue, K. Yamamoto, K. Takagi, I. Saito, K.I. Miyamoto, T. Hasegawa and T. Kondo: Environ. Res. 109, 175180 (2009).

40) K. C. Ahn, S. J. Ma, H. J. Tsai, S. J. Gee and B. D. Hammock: Anal. Bioanal. Chem. 384, 713-722 (2006).

41) H.J. Kim, K.C. Ahn, S.J. Ma, S.J. Gee and B.D. Hammock: J. Agric. Food Chem. 55, 3750-3757 (2007).
42) G. Shan, H. Huang, D. W. Stoutamire, S. J. Gee, G. Leng and B. D. Hammock: Chem. Res. Toxicol. 17, 218-225. (2004)

43) H. J. Kim, K. C. Ahn, A. Gonzalez-Techera, G. G. GonzalezSapienza, S. J. Gee and B. D. Hammock: Anal. Biochem. 386, 45-52 (2009).

44) D. B. Barr, G. Leng, E. Berger-Preiss, H. W. Hoppe, G. Weerasekera, W. Gries, S. Gerling, J. Perez, K. Smith, L. L. Needham and J. Angerer: Anal. Bioanal. Chem. 389, 811-818 (2007)

45) Y. Hu, J. Beach, J. Raymer and M. Gardner: J. Expo. Anal. Environ. Epidemiol. 14, 378-384 (2004).

46) U. Heudorf, W. Butte, C. Schulz and J. Angerer: Int. J. Hyg. Environ. Health 209, 293-299 (2006).

47) D. Wang, M. Kamijima, R. Imai, T. Suzuki, Y. Kameda, K. Asai, A. Okamura, H. Naito, J. Ueyama, I. Saito, T. Nakajima, M. Goto, E. Shibata, T. Kondo, K. Takagi, K. Takagi and S. Wakusawa: J. Occup. Health 49, 509-514 (2007).

48) J. Hardt and J. Angerer: Int. Arch. Occup. Environ. Health 76, 492-498 (2003).

49) U.S. EPA: Pesticides: Health and Safety. (2008) Available at 〈http://www.epa.gov/pesticides/food/pest.htm〉

50) F. Diel, B. Horr, H. Borck and T. Irman-Florjanc: Inflamm. Res. 52, 154-163 (2003).

51) P. Liu, X. Song, W. Yuan, W. Wen, X. Wu, J. Li and X. Chen: Arch. Toxicol. 80, 449-457 (2006).

52) D. A. Righi and J. Palermo-Neto: Toxicology 212, 98-106 (2005).

53) N. Tuzmen, N. Candan, E. Kaya and N. Demiryas: Cell Biochem. Funct. 26, 119-124 (2008).

54) A. Wu, L. Li and Y. Liu: Toxicol. Appl. Pharmacol. 187, 50-57 (2003)

55) M. I. Yousef, T. I. Awad and E. H. Mohamed: Toxicology 227, 240-247 (2006)

56) S. Y. Zhang, Y. Ito, O. Yamanoshita, Y. Yanagiba, M. Kobayashi, K. Taya, C. Li, A. Okamura, M. Miyata, J. Ueyama, C. H. Lee, M. Kamijima and T. Nakajima: Endocrinology 148, 3941-3949 (2007).

57) A. R. McCarthy, B. M. Thomson, I. C. Shaw and A. D. Abell: J. Environ. Monit. 8, 197-202 (2006).

58) M. Kojima, K. Fukunaga, M. Sasaki, M. Nakamura, M. Tsuji and T. Nishiyama: Int. J. Environ. Health Res. 15, 271-280 (2005).

59) Q. Bian, L. C. Xu, S. L. Wang, Y. K. Xia, L. F. Tan, J. F. Chen, L. Song, H. C. Chang, X. R: Occup. Environ. Med. 61, 9991005 (2004).

60) M. Kamijima, H. Hibi, M. Gotoh, K. Taki, I. Saito, H. Wang, S. Itohara, T. Yamada, G. Ichihara, E. Shibata, T. Nakajima and Y. Takeuchi: J. Occup. Health 46, 109-118 (2004).

61) K. H. Kühn, G. Leng, K. A. Bucholski, J. Dunemann and H. Idel: Chromatographia 43, 285-292 (1996).

62) J. Angerer and A. Ritter: J. Chromatogr. B Biomed. Sci. Appl. 695, 217-226 (1997).

63) S. E. Baker, D. B. Barr, W. J. Driskell, M. D. Beeson and L. L. Needham: J. Expo. Anal. Environ. Epidemiol. 10, 789-798 (2000).

64) T. Schettgen, H. M. Koch, H. Drexler and J. Angerer: J. Chromatogr. B Analyt. Technol. Biomed. Life Sci. 778, 121-130 
(2002)

65) A. O. Olsson, S. E. Baker, J. V. Nguyen, L. C. Romanoff, S.O Udunka, R. D. Walker, K. L. Flemmen and D. B. Barr: Anal. Chem. 762, 453-461 (2004).

66) S. E. Baker, A. O. Olsson and D. B. Barr: Arch. Environ. Contam. Toxicol. 46, 281-288 (2004).

67) G. Leng and W. Gries: J. Chromatogr. B Analyt. Technol. Biomed. Life Sci. 814, 285-294 (2005).

68) A. Bradman, D. B. Barr, B. G. Claus Henn, T. Drumheller, C. Curry and B. Eskenazi: Environ. Health Perspect. 111, 17791782 (2003).
69) G. S. Berkowitz, J. Obel, E. Deych, R. Lapinski, J. Godbold, Z. Liu, P. J. Landrigan and M. S. Wolff: Environ. Health Perspect. 111, 79-84 (2003).

70) P. Panuwet, T. Prapamontol, S. Chantara and D. B. Barr: Int. J. Hyg. Environ. Health 212, 288-297 (2009).

71) R. H. Hill, Jr., D. B. Shealy, S. L. Head, C. C. Williams, S.L. Bailey, M. Gregg, S. E. Baker and L. L. Needham: J. Anal. Toxicol. 19, 323-329 (1995).

72) C. Aprea, A. Stridori and G. Sciarra, J. Chromatogr. B Biomed. Sci. Appl. 695, 227-236 (1997). 